Article

\title{
New Twin-Roll Cast Al-Li Based Alloys for High-Strength Applications
}

\author{
Olexandr Grydin ${ }^{1, *}$, Mykhailo Stolbchenko ${ }^{1}$,, Mirko Schaper $^{1}$, Sára Belejová ${ }^{2}$, \\ Rostislav Králík ${ }^{2}$, Lucia Bajtošová ${ }^{2}$, Barbora Křivská ${ }^{2}$, Michal Hájek ${ }^{2}$ and Miroslav Cieslar ${ }^{2}$ (D) \\ 1 Chair of Materials Science, Paderborn University, Warburger Str. 100, 33098 Paderborn, Germany; \\ stolbchenko@lwk.upb.de (M.S.); schaper@lwk.upb.de (M.S.) \\ 2 Faculty of Mathematics and Physics, Charles University, Ke Karlovu 5, 12116 Prague 2, Czech Republic; \\ sara.belejova@gmail.com (S.B.); rkralik96@gmail.com (R.K.); lucibajtos@gmail.com (L.B.); \\ krivska.barbora@seznam.cz (B.K.); hajek1@karlov.mff.cuni.cz (M.H.); cieslar@met.mff.cuni.cz (M.C.) \\ * Correspondence: grydin@lwk.upb.de; Tel.: +49-5251-60-4228
}

Received: 30 June 2020; Accepted: 18 July 2020; Published: 22 July 2020

\begin{abstract}
Al-Li based alloys are attractive materials for the aerospace industry. The twin-roll casting of such materials could provide properties not achievable by conventional direct-chill casting and downstream processing methods due to significantly higher solidification rates. An Al-Li-Cu-Mg-Zr alloy was twin-roll cast with the same alloy containing a small addition of Sc. The microstructure of as-cast materials and the influence of Sc on the behavior of the alloy at elevated temperatures were studied by means of light and electron microscopy and by resistivity measurements. A fine-grained structure was formed during twin-roll casting, but several surface and internal defects were found on the strips, which should be suppressed by a further adjustment of the casting conditions. The addition of Sc had a positive effect on grain size uniformity and microstructure stabilization at elevated temperatures, as shown by the precipitation of a fine dispersion of coherent Sc- and Zr-containing precipitates.
\end{abstract}

Keywords: twin-roll casting; Al-Li-Cu-Mg-Zr alloy; Sc alloying; microstructure stabilization

\section{Introduction}

Recently, Al-Li alloys have found increasing use in weight and stiffness critical structures for aircraft and aerospace applications as they have better properties (low density and high specific strength) than structures made of commercial Al alloys [1-4]. The superior properties of Al-Li alloys are mainly attributed to the added $\mathrm{Li}$, which influences the weight reduction and elastic modulus. One wt. $\%$ of Li reduces the density of the resulting $\mathrm{Al}$ alloy by approximately $3 \%$ and increases the elastic modulus by approximately $6 \%[4,5]$. The addition of $\mathrm{Li}$ to $\mathrm{Al}$ produces fine precipitates, which improve the stiffness and strength of the $\mathrm{Al}$ alloys [6]. These aspects make $\mathrm{Li}$ the optimum metallic element for $\mathrm{Al}$ alloys used in the aircraft industry. Al-Li alloys also have a higher resistance to fatigue crack growth and stress corrosion cracking than traditional $\mathrm{Al}$ alloys $[7,8]$. The solution of $\mathrm{Li}$ in the $\mathrm{Al}$ matrix accounts for only a small part of solid solution strengthening, which is mainly caused by the variation of the elastic modulus and size of the $\mathrm{Li}$ and $\mathrm{Al}$ atoms. Secondly, the main strengthening in $\mathrm{Al}-\mathrm{Li}$ alloys is generally due to a huge volume fraction of the $\mathrm{Al}_{3} \mathrm{Li}\left(\delta^{\prime}\right)$ phase, which is the main reason for the high elastic modulus observed in these alloys, since $\mathrm{Al}_{3} \mathrm{Li}$ itself has a large intrinsic modulus $[3,4,9]$.

Other alloying elements such as $\mathrm{Cu}$ and $\mathrm{Mg}$ are often added to $\mathrm{Al}-\mathrm{Li}$ alloys to produce different strengthening phases, as they have shown to be efficient in strengthening [3,10]. $\mathrm{Cu}$ and $\mathrm{Mg}$ contribute to improving the precipitation order either by forming $\mathrm{Cu}$ - and $\mathrm{Mg}$-based phases and co-precipitating 
with the $\mathrm{Al}_{3} \mathrm{Li}$ or by altering the solubility of the most important alloying elements [11]. In addition, they can also interact with $\mathrm{Li}$ to precipitate as solidification phases, which occur in quaternary (Al-Li-Cu-Mg) and ternary (Al-Li-Cu) alloys. In Al-Li-Cu alloys, additional strengthening phases were obtained by co-precipitation of $\mathrm{Cu}$-based phases such as $\mathrm{Al}_{2} \mathrm{CuLi}\left(\mathrm{T}_{1}\right)$ and $\mathrm{Al}_{6} \mathrm{CuLi}_{3}\left(\mathrm{~T}_{2}\right)$ [3]. The addition of $\mathrm{Mg}$ to $\mathrm{Al}-\mathrm{Li}$ alloys creates $\mathrm{Al}_{2} \mathrm{CuMg}\left(\mathrm{S}^{\prime}\right)$ near the grain boundaries (GBs), which reduce/eliminate the precipitation-free zones. The reduction of the precipitation free zones helps to prevent early failure and improve the strength of Al-Li alloys, as the combinations of coarse grain boundary precipitates and precipitation free zones allow the localized slip to generate stress concentrations that form voids at the grain boundary precipitates $[12,13]$. The existence of $\mathrm{Al}_{2} \mathrm{CuLi}$ precipitates is important for increasing strength as they act as a non-shearable barrier that must be overcome by dislocations during deformation.

However, in addition to the benefits obtained by adding Li to Al, the ductility, formability, and fracture toughness - as well as the anisotropic mechanical properties - of Al-Li alloys are reduced, which in turn limits the commercial application of this type of alloy [4]. The factors that have a negative influence on tensile deformation and formability in Al-Li alloys are planar deformation and strain localization due to the $\mathrm{Al}_{3} \mathrm{Li}$ phases shearing [14], slip localization on the $\mathrm{Al}_{3} \mathrm{Li}$ precipitation free zones created during artificial ageing [15], coarse equilibrium phases, such as $\mathrm{Al}-\mathrm{Li}, \mathrm{Al}_{2} \mathrm{CuLi}$, and $\mathrm{Al}_{6} \mathrm{CuLi}_{3}$ [16], and crack propagation at the sub-grain and grain boundaries, especially in non-recrystallized alloys [17]. Adjusting the deformation mode from a dislocation shearing of the strengthening phases to a bypass can reduce the strain localization in the alloy matrix. The easiest way to accomplish this is to reduce the grain size, control the recrystallization degree [18], and add alloying elements such as $\mathrm{Mg}$ and $\mathrm{Cu}$ to create non-shearable strengthening phases [19]. Additions of scandium and zirconium also offer an attractive combination of properties. The precipitation of metastable $\mathrm{Al}_{3} \mathrm{Sc}_{1-\mathrm{x}} \mathrm{Zr}_{\mathrm{x}}$ [20] particles after aging contributes to precipitation hardening and thus increases the strength values of the alloy. The precipitates form at temperatures above $300{ }^{\circ} \mathrm{C}$ (typically $350{ }^{\circ} \mathrm{C}$ ) and serve as highly effective barriers to dislocation and grain boundary motion. At higher temperatures, however, they transform into a coarse equilibrium phase [20], whereby the strengthening effect is lost. This new phase is stable almost to the melting point of the alloy and could therefore not be dissolved by any solution treatment. The formation of the pancake shape of grains and the precipitation of a stable $\mathrm{Al}_{3} \mathrm{Sc}_{1-x} \mathrm{Zr}_{x}$ phase thus exclude the possibility of grain boundary formation through the thermo-mechanical treatment of conventional direct-chill cast and rolled sheets, since the two critical conditions (recrystallization, which occurs only at high temperatures, and the presence of a fine dispersion of metastable $\mathrm{Al}_{3} \mathrm{Sc}_{1-x} \mathrm{Zr}_{\mathrm{x}}$, which is no more stable at recrystallization temperatures) could not be fulfilled simultaneously.

An alternative procedure is the direct casting of sheets to the final thickness (typically 3-8 mm) by continuous casting (for instance twin-roll casting (TRC) [21]) without the need for subsequent rolling steps. Grains formed during the solidification of TRC strips are usually rather equiaxed with a low density of dislocations, often organized in rare dislocation cell walls or incorporated in low angle boundaries. Therefore, no additional recrystallization treatment is necessary in order to remove any undesirable directional structure.

The distinctive feature of TRC is the combination of rapid metal solidification and subsequent plastic reduction in a single combined processing step. During the TRC, a liquid melt is fed between two internally cooled, rotating rolls. As a result of the intensive heat transfer to the coolant via the casting rolls, the melt solidifies and undergoes a plastic reduction similar to the rolling process. Finally, the metal leaves the caster in form of a solid thin strip [21]. Thus, the number of intermediate heating cycles required and the amount of rolling operations in the downstream processing could be significantly reduced or even completely eliminated in comparison with conventional technologies. They could also be replaced by non-standard methods developed in the last decades known as continuous severe plastic deformation methods, which suppress the formation of a directional structure 
during rolling, e.g., constrained groove pressing or rolling, repetitive corrugation and straightening, or continuous confined strip shearing [22-24].

The cooling rate during twin-roll casting can reach $10^{3} \mathrm{~K} / \mathrm{s}$, which is much higher than in other casting processes [25]. The high solidification rate enables the formation of a fine dendritic microstructure with fine intermetallic precipitations. Thus, a relatively high content of alloying elements in high-alloyed alloys can be distributed almost homogeneously in the strip without a significant macroscopic gradient, which is unavoidable with direct-chill cast ingots [26]. In this case, metastable intermetallic phases can precipitate, which are otherwise not present [27].

TRC was successfully applied for the industrial production of strips of aluminum alloys with a relatively low alloying element content (under $2.5 \mathrm{wt} . \%$ ), such as pure aluminum [28] and self-hardening Al-Mn alloys [29,30], as well as Al-Fe-Si alloys [31]. Thin strips of Al-Mg alloys with less than $3 \mathrm{wt} . \%$ $\mathrm{Mg}[2,28]$ are also twin-roll cast in appropriate quality on an industrial scale. At the same time, TRC of strips of Al-Mg alloys with up to $4.5 \mathrm{wt} . \% \mathrm{Mg}[32,33]$ is limited predominantly to laboratory scale. The industrial twin-roll casting of thin strips of age-hardenable alloys is limited to the alloy EN AW-6016 [34]. However, extensive research is being conducted on the application of age-hardenable alloys for twin-roll casting. Strips of age-hardenable Al-Mg-Si alloys [35,36] and Al-Zn-Mg alloys were successfully manufactured on laboratory scale by means of twin-roll casters [26,36]. First laboratory attempts to prepare $5 \mathrm{~mm}$ thick strips from Al-Mg-Sc-Zr alloy by TRC showed a positive effect of Sc and $\mathrm{Zr}$ alloying on the stability of deformation structures formed during TRC [37]. Attempts to use TRC for the production of Al-Li based alloys are limited [38] and no such alloy containing Sc has ever been manufactured by TRC.

However, some specific microstructural features of TRC strips are known to restrict the applications of this technology. These are localized centerline segregation, surface and near-surface microsegregation and microstructural inhomogeneity [25]. These characteristics might lead to the deterioration of the mechanical properties of the strips, in particular strength, formability and corrosion resistance, and can only be partially suppressed by a microstructure transformation during a complex thermomechanical treatment. The aim of the work is a description of the microstructure of thin strips of an Al-Li-Cu-Mg-Zr-alloy prepared by twin-roll casting and an evaluation of the influence of $\mathrm{Sc}$ as an alloying element on the microstructure of the as-cast material and on the behavior of the material during subsequent exposure to elevated temperatures.

\section{Materials and Methods}

An Al-Li-Cu-Mg-Zr alloy (see Table 1) was used as the input material for the twin-roll casting trials. The content of the alloying and accompanying elements was measured with an optical emission spectrometer Q4 TASMAN from Bruker AXS GmbH (Karlsruhe, Germany). In addition, a master alloy containing Sc was produced for a modification of the base aluminum alloy. For this purpose, $1519 \mathrm{~g}$ of $99.995 \%$ purity aluminum were molten in a resistance furnace in an argon-protected atmosphere in a graphite crucible and overheated to $900{ }^{\circ} \mathrm{C}$. Then, $31 \mathrm{~g}$ of pure scandium were added to the overheated melt and soaked for $25 \mathrm{~min}$. During the last $7 \mathrm{~min}$ of soaking, the melt was mechanically stirred using a stirrer with steel blades coated with boron nitride. After soaking, the melt was poured into a steel mold whose interior was coated with boron nitride as well. The chemical composition of the solidified material was analyzed by means of an energy-dispersive $X$-ray spectroscope from EDAX (Mahwah, USA) installed in a Zeiss Ultra Plus scanning electron microscope (Oberkochen, Germany). The large-scale mapping measurements, which were carried out with an acceleration voltage of $20 \mathrm{kV}$, yielded an aluminum content of $96.64 \mathrm{wt} . \%$, a scandium content of $2.44 \mathrm{wt} . \%$ and an iron content of $0.92 \mathrm{wt} . \%$ in the master alloy.

Subsequently, two twin-roll cast trials were conducted to produce $3 \mathrm{~mm}$ thick strips of a non-modified Al-Li-Cu-Mg-Zr alloy and a modified with Sc aluminum alloy. The experiments were performed using the laboratory twin-roll caster of the Paderborn University. The assembled water-cooled rolls of the machine are equipped with steel shells with an outer diameter of $370 \mathrm{~mm}$ and 
a barrel length of $200 \mathrm{~mm}$. The rolls are driven by an electric motor with a power of $11 \mathrm{~kW}$. A detailed description of the twin-roll caster is provided in [39].

Table 1. Chemical composition of the input aluminum alloy.

\begin{tabular}{cccccccccccc}
\hline Element & $\mathbf{C u}$ & $\mathbf{L i}$ & $\mathbf{M g}$ & $\mathbf{Z r}$ & $\mathbf{S c}$ & $\mathbf{A g}$ & $\mathbf{T i}$ & $\mathbf{V}$ & $\mathbf{F e}$ & $\mathbf{A l}$ & Other \\
\hline Content, wt.\% & 3.71 & 0.91 & 0.31 & 0.15 & 0 & 0.33 & 0.02 & 0.01 & 0.05 & 94.49 & Balance \\
\hline
\end{tabular}

The experiments were realized in a vertical operating plane. In the first trial, $7016 \mathrm{~g}$ of the base aluminum alloy with the chemical composition given in Table 1 and $702 \mathrm{~g}$ of commercial aluminum were used, while in the second trial $7468 \mathrm{~g}$ of the basic Al-Li-Cu-Mg-Zr-alloy was used with the addition of $746 \mathrm{~g}$ of the previously fabricated Sc-containing master alloy. The basic alloy with additives was molten in an in-house designed resistance furnace mounted on the top of the twin-roll caster. The furnace, the tundish with the ceramic nozzle fixed on its bottom, and the roll gap were flooded with argon to avoid exothermic oxidation of lithium. To prevent segregation of the scandium in the melt due to gravity, the melt was continuously mechanically stirred in the furnace before and during casting. No release agents were utilized to coat the shells before or during the trials. In both tests, casting was performed at a pouring temperature of $660{ }^{\circ} \mathrm{C}$ and a casting rate of $3.6 \mathrm{~m} / \mathrm{min}$. Previous studies by the authors have shown that at such casting rates, the propagation of near-surface segregation from the surface to the strip core, which can deteriorate the mechanical and corrosive properties of twin-roll cast strips, is not pronounced $[40,41]$. The roll separating force (RSF) in both experiments was approx. $200 \mathrm{kN}$, which corresponds to a specific RSF of $1 \mathrm{kN} / \mathrm{mm}$. Chemical compositions of the twin-roll cast strips measured by optical emission spectrometry are given in Table 2.

Table 2. Chemical compositions of twin-roll cast strips.

\begin{tabular}{cccccccccccc}
\hline Without Sc Addition & $\mathbf{C u}$ & $\mathbf{L i}$ & $\mathbf{M g}$ & $\mathbf{Z r}$ & $\mathbf{S c}$ & $\mathbf{A g}$ & $\mathbf{T i}$ & $\mathbf{V}$ & $\mathbf{F e}$ & $\mathbf{A l}$ & Other \\
\hline Content, wt. $\%$ & 2.52 & 0.72 & 0.27 & 0.12 & - & 0.33 & 0.02 & 0.01 & 0.09 & 95.99 & Balance \\
\hline With Sc addition & $\mathbf{C u}$ & $\mathbf{L i}$ & $\mathbf{M g}$ & $\mathbf{Z r}$ & $\mathbf{S c}$ & $\mathbf{A g}$ & $\mathrm{Ti}$ & $\mathbf{V}$ & $\mathbf{F e}$ & $\mathbf{A l}$ & Other \\
\hline Content, wt. $\%$ & 2.61 & 0.71 & 0.27 & 0.10 & 0.17 & 0.29 & 0.01 & 0.01 & 0.09 & 95.32 & Balance \\
\hline
\end{tabular}

Light optical microscopy (LOM) observations were performed using Zeiss Axio Observer metallographic microscope (Jena, Germany). Transmission electron microscopy (TEM) was carried out with the microscopes JEOL JEM 2000F and JEOL JEM 2200 FS (Tokyo, Japan), both operating at an accelerating voltage of $200 \mathrm{kV}$. The samples for the LOM were mechanically polished and finally etched in $0.5 \% \mathrm{HF}$ in distilled water for $5 \mathrm{~s}$ to map the distribution of the primary phases. Electrolytic anodization using Barker's-5 mL $\mathrm{HBF}_{4}$ in $200 \mathrm{~mL}$ water at $10{ }^{\circ} \mathrm{C}$ was used for grain observation. The specimens for the TEM were electropolished in $30 \% \mathrm{HNO}_{3}$ solution in methanol at temperatures near $-20^{\circ} \mathrm{C}$.

A standard four-point method was used for in-situ resistivity changes measurements. Voltage and electrical current were measured simultaneously using nanovoltmeter Keithley 2182 (Beaverton, OR, USA) and SourceMeterKeithley 2400 devices (Beaverton, OR, USA), respectively. Specimens were placed in an in-house designed furnace enabling precise heating of the specimen in an argon protective atmosphere. Normalized resistivity curves could provide integral information about a redistribution of solute atoms within the matrix linked to precipitation of new phases or their dissolution. Derivative curves map the dynamics of microstructural changes.

\section{Results and Discussion}

\subsection{Microstructure of As-Cast Materials}

Although similar in chemical composition, the grain structures of both alloys differ considerably (Figure 1). The resulting as-cast structures clearly show a positive influence of added Sc on grain 
refinement and the uniformity of their size. However, the grains in the Sc-containing alloy are rather equiaxed, with an approximately $1 \mathrm{~mm}$ thick central band consisting of considerably finer grains. This pattern occurs along the entire length and width of the strip, as demonstrated on the sections in the transverse (TD) and rolling (RD) directions (Figure 1a,b). This feature was confirmed also for the second strip, which was cast under the same conditions. In contrast, the Sc-free alloy exhibits significantly uneven grain sizes even within one strip. A rather uniform structure of two already solidified skins with grains inclined in the rolling direction, which were welded together during the TRC process, can be observed in the center of the strip (Figure 1c). However, within a few millimeters this structure changes to an inhomogeneous one with bands of fine grains, which are located near both surfaces of the strip and in the center of the strip. Corresponding irregularities were also found in the section perpendicular to the RD (Figure 1d), revealing channels with fine grains close to the surface and center of the strip.

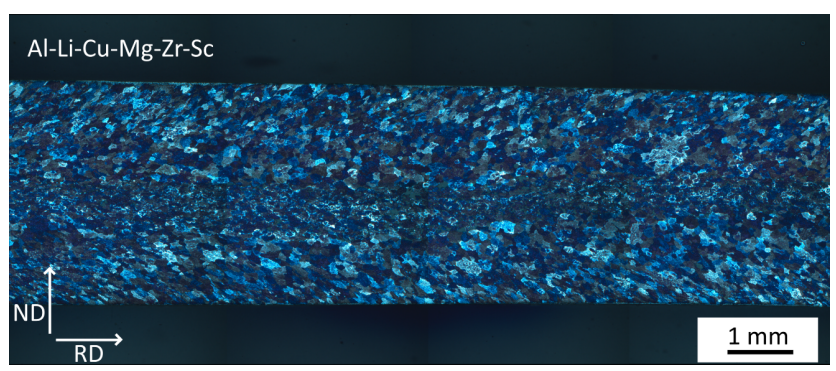

(a)

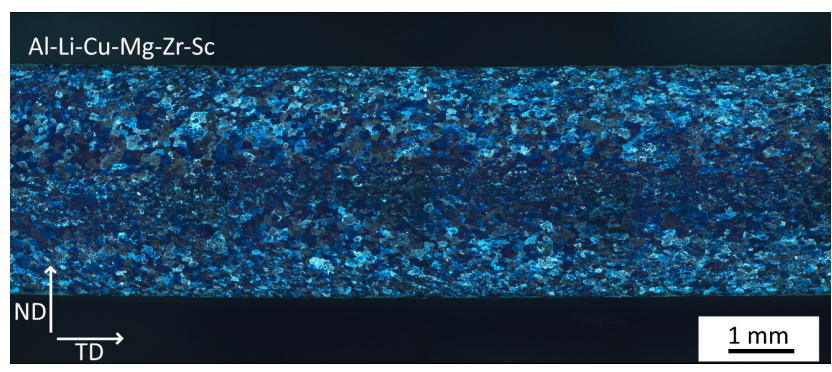

(b)

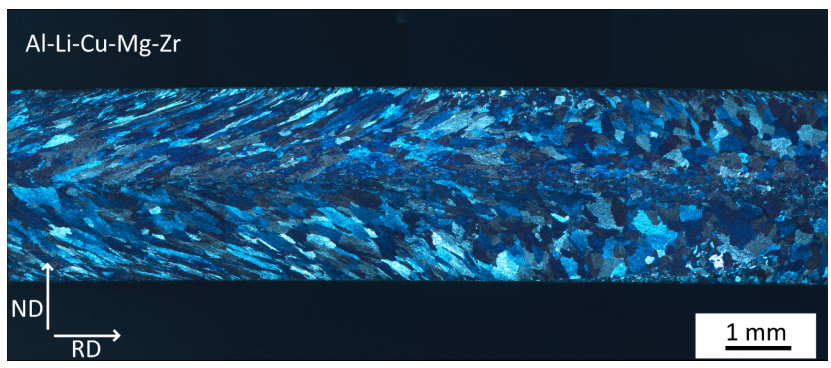

(c)

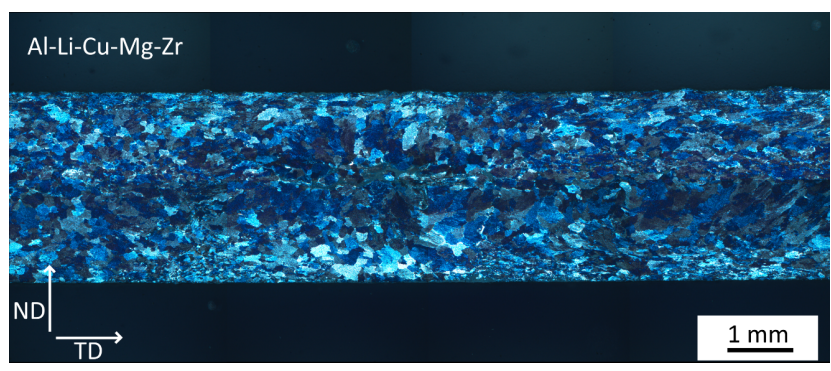

(d)

Figure 1. Grain microstructure in as-cast Al-Li-Cu-Mg-Zr-Sc (a,b) and Al-Li-Cu-Mg-Zr (c,d) alloys in sections perpendicular to transverse $(\mathbf{a}, \mathbf{c})$ and rolling $(\mathbf{b}, \mathbf{d})$ directions. ND stands for normal direction. 
The grain structure mentioned above reflects patterns of fine dendritic structures observed on etched samples. A pronounced inhomogeneity of the grain size distribution over the thickness of all strips in Figure 1 is mirrored by arrangements of centerline and near-surface segregations in Figure 2, dendritic segregations in Figure 3 as well. The grain structure mentioned above reflects patterns of fine dendritic structures, which are visible on etched samples in Figure 3. Bands of finer grains observed in the center of the Al-Li-Cu-Mg-Zr-Sc alloy and in some parts of the Al-Li-Cu-Mg-Zr alloy (central parts in Figure 2a,b,d, and the central part located in the right half of the specimen in Figure 2c) occur when the semi-solid, soft core layer moves against the rolling direction. As a result, it solidifies entirely and develops a very fine globulitic grain structure [42]. Isolated coarse grains are the consequence of an extensive growth of the broken dendrite tips [43]. The core layer of both strips contains deformation segregates. According to Yun et al. [42], these segregates occur when the deformation process during TRC is so rapid that the already solidified shells, which are located close to the cooled rolls, and the liquid in between are deformed together. During this deformation process, small liquid regions form between the solid grain. In accordance with [42], these regions do not form elongated channels, but rather small grains with small secondary arm spacing (Figure 3a,b). The central part of the Al-Li-Cu-Mg-Zr strip in Figures $1 \mathrm{~d}$ and $2 \mathrm{~d}$ contains channel segregates as well [44]. Their formation is associated with the deformation of a semisolid material in a mushy zone between the rolls [42]. This deformation squeezes the liquid back towards the sump. When liquid flows intergranular from a cold to a hot area, the liquid should change its composition and this melts parts of dendrites. Thus, the intergranular backwards flow leads to remelting, to further flow and thus to channel formation [42]. Furthermore, supersaturated near-surface bands in the Al-Li-Cu-Mg-Zr-Sc alloy (Figure 3c) and surface bleeds in the Al-Li-Cu-Mg-Zr-Sc (Figure 3d) were observed. According to Monaghan et al. [45], the latter are pockets with a material significantly enriched with solutes. They form as a result of the solidification of a small amount of solute-rich liquid, which can fill small gaps or small buckles between the roll and the semi-solid shell when compressive forces induce backward slipping during the deformation of solid and semi-solid material.

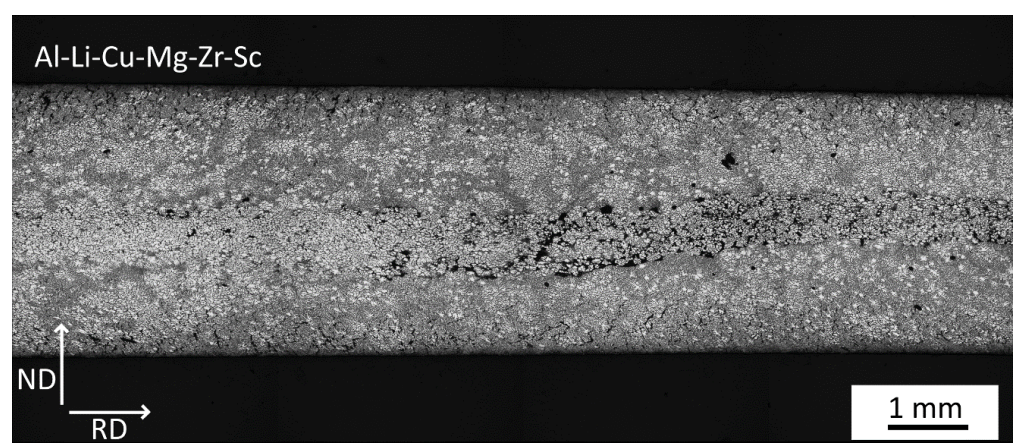

(a)

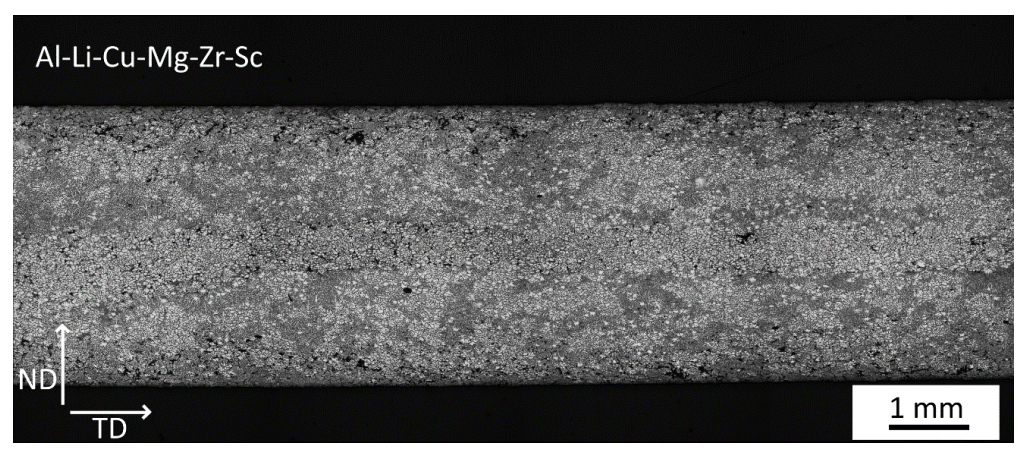

(b)

Figure 2. Cont. 


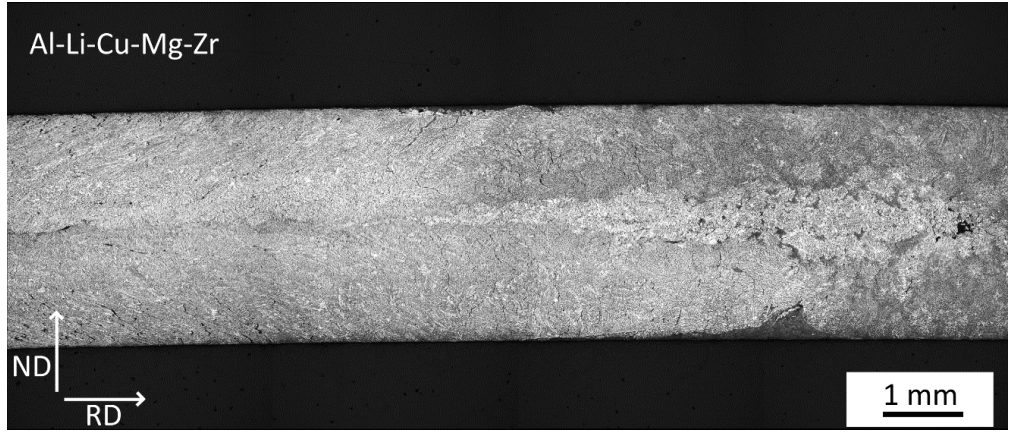

(c)

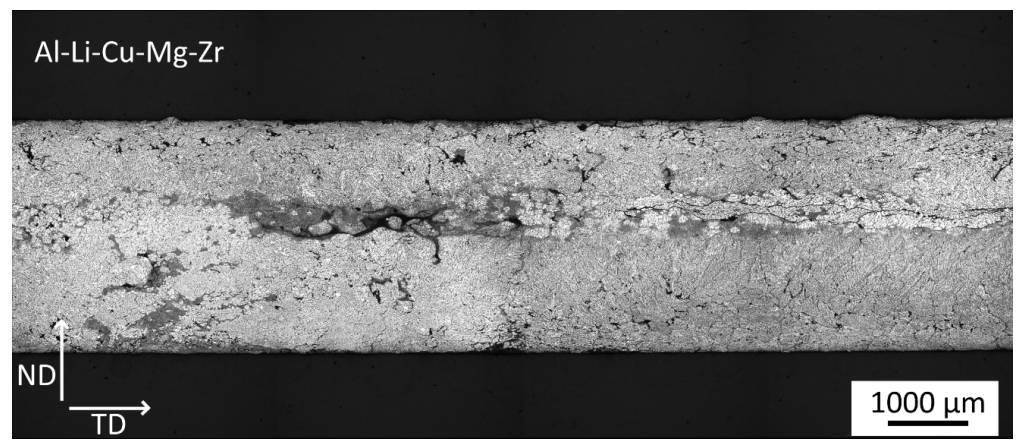

(d)

Figure 2. Microstructure on the transverse $(\mathbf{a}, \mathbf{c})$ and longitudinal $(\mathbf{b}, \mathbf{d})$ sections from Figure 1 of as-cast $\mathrm{Al}-\mathrm{Li}-\mathrm{Cu}-\mathrm{Mg}-\mathrm{Zr}-\mathrm{Sc}(\mathbf{a}, \mathbf{b})$ and Al-Li-Cu-Mg-Zr (c,d) alloys.

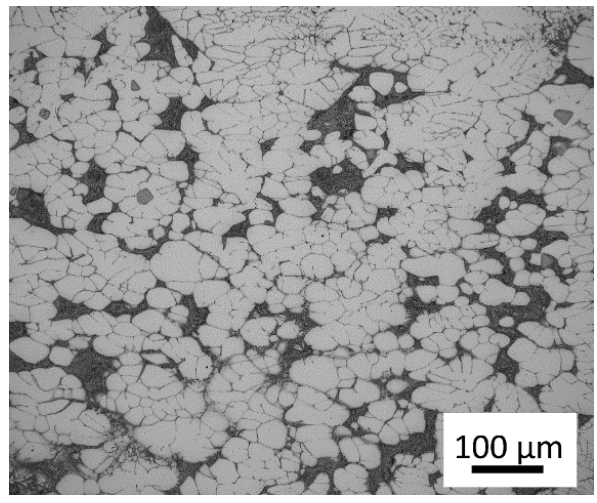

(a)

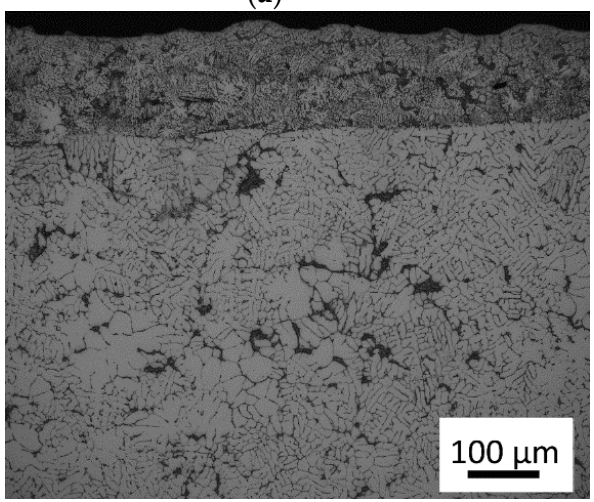

(c)

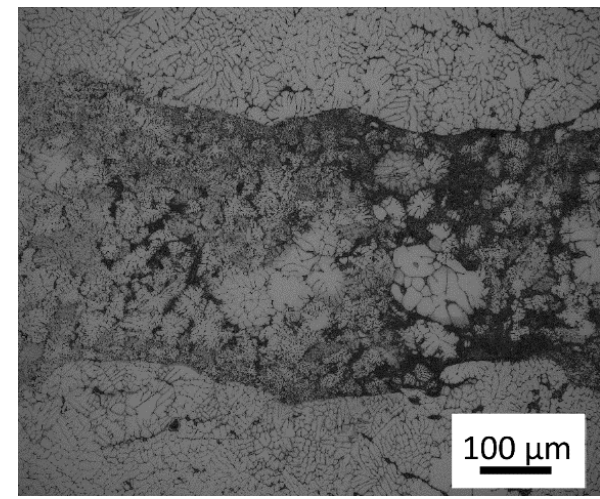

(b)

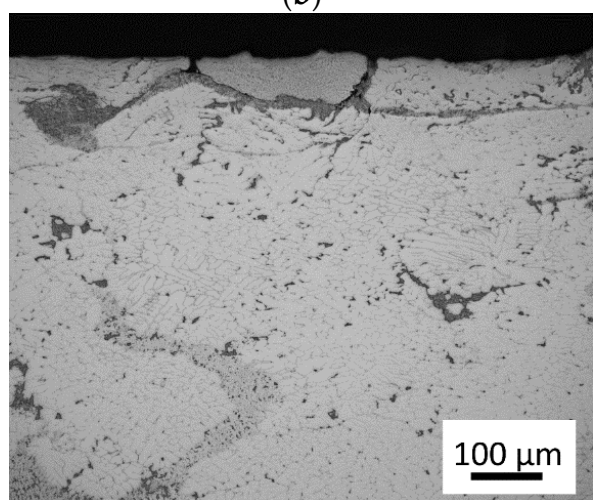

(d)

Figure 3. Microstructure of central bands in the Al-Li-Cu-Mg-Zr-Sc alloy in transverse (a) and longitudinal (b) sections. Supersaturated near-surface bands in the Al-Li-Cu-Mg-Zr-Sc strip (c) and surface bleeds in the Al-Li-Cu-Mg-Zr (d) alloy, longitudinal sections. 
Further details of the initial microstructure were obtained by electron microscopy (Figure 4). Only the results on the Al-Li-Cu-Mg-Zr-Sc material are presented, since the microstructure of the Al-Li-Cu-Mg-Zr alloy has identical properties. The TEM experiments revealed $\mathrm{Cu}$ - and $\mathrm{Mg}$-rich primary particles on the grain boundaries of the partially recovered and partially recrystallized microstructure (Figure 4a). Although the presence of Li could not be excluded, a first rough analysis of the diffraction patterns shows $\mathrm{T}_{2}\left(\mathrm{Al}_{6} \mathrm{CuLi}_{3}\right)$ and equilibrium $\mathrm{Al}_{2} \mathrm{Cu}$ phases. Laths of non-equilibrium $\mathrm{S}^{\prime}\left(\mathrm{Al}_{2} \mathrm{CuMg}\right)$ rarely occur in both materials as a result of the air cooling after TRC (Figure 4b). As was to be expected, no equilibrium AlLi or non-equilibrium $\mathrm{Al}_{3} \mathrm{Li}$ particles were detected, as they generally do not form in third generation Al-Li based alloys [46,47] with low Li and high Cu contents. Figure 4c shows the distribution of small Ag particles created as a result of a small addition of this element to the alloy. Ag typically modifies the formation kinetics of the main strengthening phase in third generation alloys, the $\mathrm{T} 1\left(\mathrm{Al}_{2} \mathrm{CuLi}\right)$ phase [48]. Even at very high magnifications, no signs of $\mathrm{Al}_{3} \mathrm{Sc}_{1-\mathrm{x}} \mathrm{Zr}_{\mathrm{x}}$ precipitates or early stages of Al-Cu system particles were detected in bright field or dark field TEM, however, weak diffraction spots and streaks in the diffraction pattern (Figure $4 \mathrm{~d}$ ) indicate that long-term exposure of the strip at room temperature could cause some decomposition of the supersaturated solid solution, which contains a sufficient amount of precipitate-forming elements.

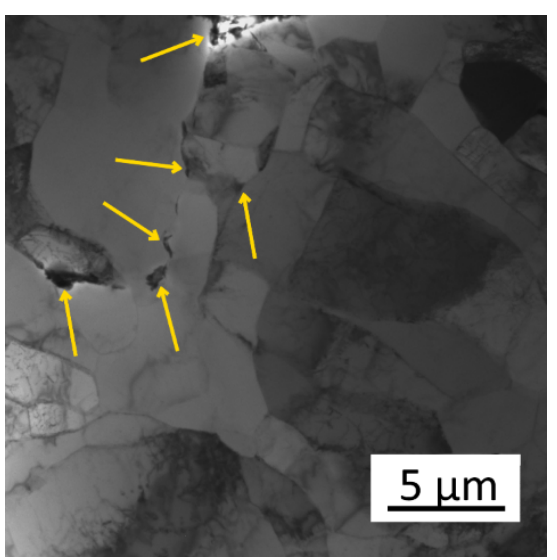

(a)

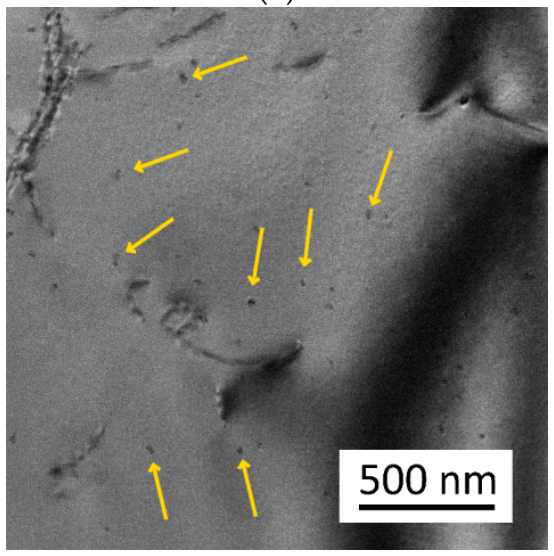

(c)

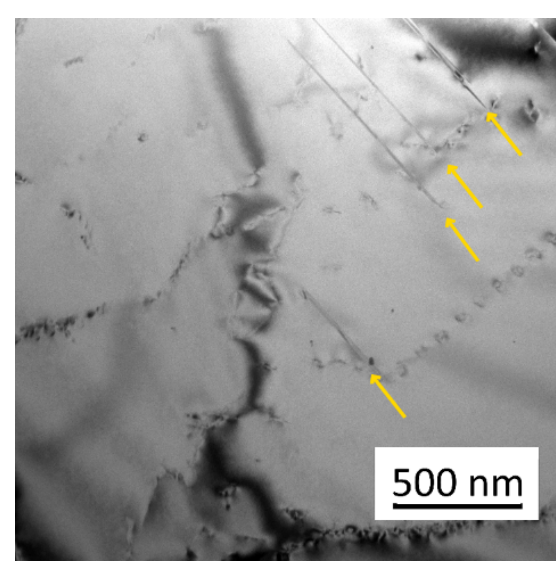

(b)

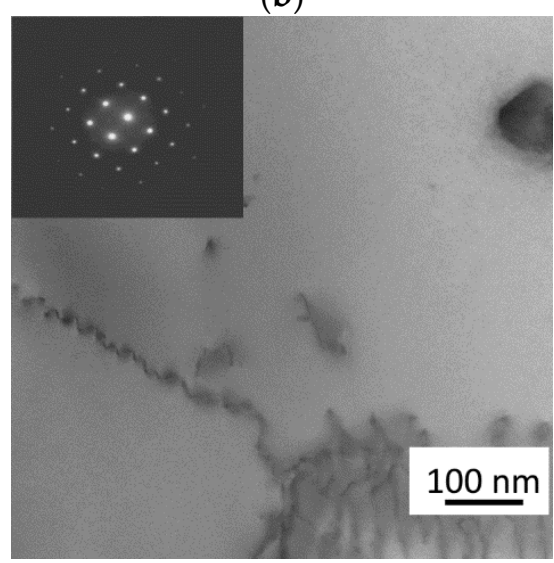

(d)

Figure 4. Transmission electron microscopy (TEM) analysis of the as cast strip of the Al-Li-Cu-Mg-Zr-Sc alloy. Bright field images showing a decoration of grain boundaries by primary phase particles (a), rare precipitates of $\mathrm{Al}_{2} \mathrm{CuMg}$ phase (b), and $\mathrm{Ag}$ particles (c). Higher magnification close to [100] Al-orientation (d). The inset shows diffraction pattern from [100] Al-zone with visible fine forbidden reflections and streaks. 


\subsection{Evolution of Microstructure during Heating}

In-situ resistivity measurements during linear heating $(1 \mathrm{~K} / \mathrm{min})$ were used for the integral characterization of the solute redistribution in both strips, since the relative resistivity is sensitive to a redistribution of solutes in the matrix. For more details about the accuracy of the method see, e.g., [49]. As Figure 5a illustrates, the evolution of resistivity mainly reflects a parabolic increase of the thermal component of resistivity. However, small modulations are evident between 200 and $400{ }^{\circ} \mathrm{C}$ in both alloys. Specific processes are emphasized in temperature derivatives of the measured curves (Figure 5b). In general, local minima indicate a depletion of the matrix of solutes, which is associated with a precipitation of new phases or a coarsening of already existing ones. The presence of local maxima, on the other hand, indicates an enrichment of the matrix with dissolved particles. As shown in Figure 5, the two materials react similarly to thermal exposure. On the derivative curves below $250{ }^{\circ} \mathrm{C}$ only small changes are visible, followed by pronounced minima between 300 and $400{ }^{\circ} \mathrm{C}$. Although the evolution of derivatives above $400{ }^{\circ} \mathrm{C}$ is again rather marginal, the most pronounced differences between both materials can be observed close to this temperature.

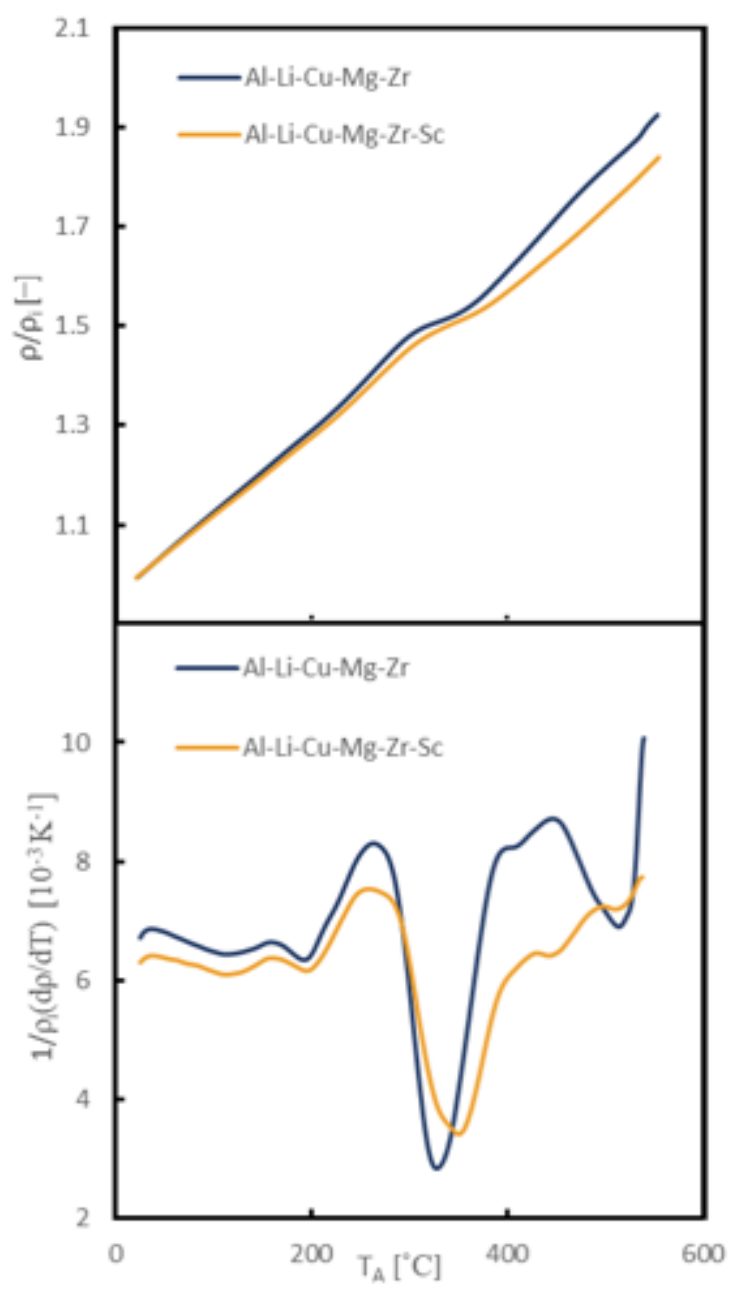

(a)

(b)

Figure 5. Evolution of resistivity in two Al-Li based alloys during linear heating (a). Temperature derivative of resistivity curves $(\mathbf{b})$.

Conventional TEM observations on selected specimens that were annealed at the same heating rate showed no significant changes in the microstructure below $250{ }^{\circ} \mathrm{C}$ as the method reached its limit. In general, changes observed in the same temperature interval in similar alloys after homogenization annealing are associated with pre-precipitation stages of the formation of $\theta^{\prime}, \mathrm{S}^{\prime}$ or $\mathrm{T} 1$ 
phases $[47,50]$. Indeed, coarser $\theta^{\prime}$ plates and $S^{\prime}$-phase needles were found in both samples annealed to $400{ }^{\circ} \mathrm{C}$ (Figure $6 \mathrm{a}, \mathrm{b}$ ). The presence of small $\mathrm{Al}_{3} \mathrm{Sc}_{1-\mathrm{x}} \mathrm{Zr}_{\mathrm{x}}$ precipitates in the $\mathrm{Al}-\mathrm{Li}-\mathrm{Cu}-\mathrm{Mg}-\mathrm{Zr}-\mathrm{Sc}$ alloy (Figure 6c) confirms that the differences in resistivity between the two alloys originate in their formation. A formation, growth, and coarsening of Sc-containing particles takes place in the Sc-containing alloy together with coarsening and dissolution of particles containing main alloying elements close to $400^{\circ} \mathrm{C}$. No changes associated with Sc could occur in Sc-free alloy. The two type of processes have an opposite influence on resistivity-dissolution of particles and matrix enrichment results in an increase of resistivity (more pronounced peak in positive direction on derivative), while formation and growth of Sc-containing particles results in a decrease of resistivity and peak in a negative direction on the derivative curves. Therefore, are the changes observed in Sc-containing alloy less evident. This result is consistent with the generally reported properties of aluminum alloys containing Sc [20]. It should be noted that primary phases are still existent at the grain boundaries. Their potential growth or enrichment with solutes could not be ruled out by the TEM experiment.

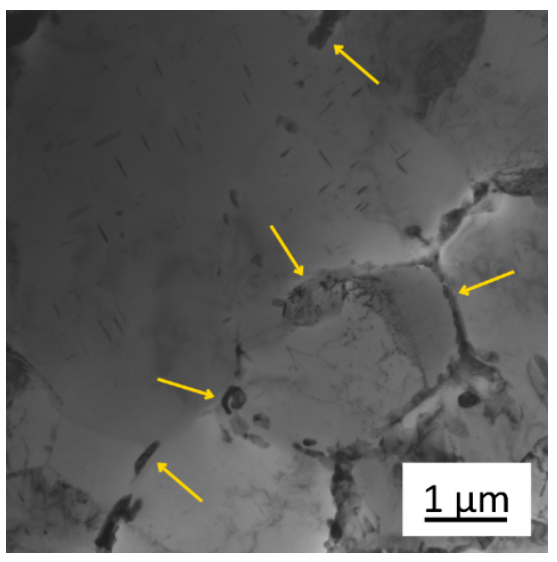

(a)

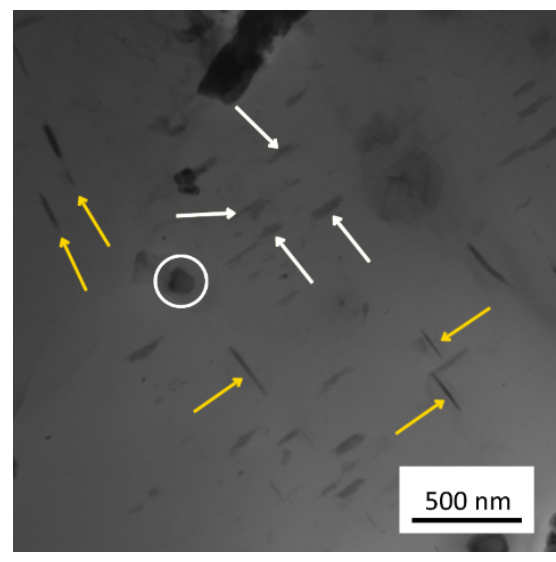

(b)

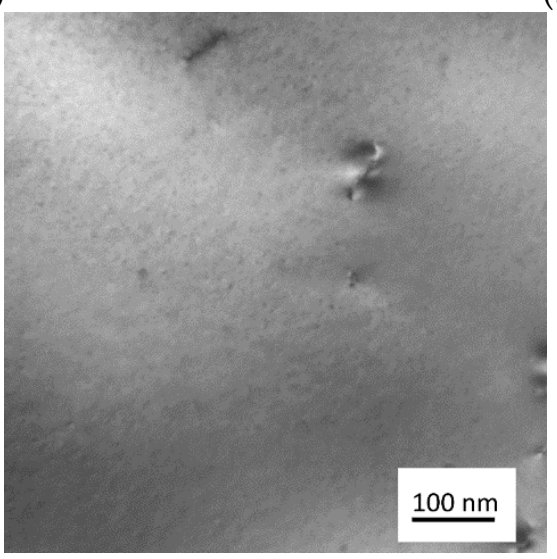

(c)

Figure 6. TEM bright field images of Al-Li-Cu-Mg-Zr-Sc alloy annealed in a linear heating regime up to $400^{\circ} \mathrm{C}$. Coarse primary phase particles on grain boundaries (a), needles of $\mathrm{S}^{\prime}$ (yellow arrows), an Ag particle (white circle) and plates of $\theta^{\prime}$ (white arrows) (b) and very fine $\mathrm{Al}_{3} \mathrm{Sc}_{1-\mathrm{x}} \mathrm{Zr}_{\mathrm{x}}$ particles spread through the whole volume (c).

Significant evolutions in the microstructure of the grain boundaries were found in both specimens annealed at up to $500{ }^{\circ} \mathrm{C}$ (Figure 7). The dissolution of the primary phases is convincing (Figure 7a-c). In addition, the microstructure of the $\mathrm{Al}-\mathrm{Li}-\mathrm{Cu}-\mathrm{Mg}$-Zr alloy shows signs of recovery and recrystallization (Figure 7a,b). No visible changes of (sub)grain size could be detected by TEM (Figure 7c), most likely due to sufficient Zener drag [51] created by $\mathrm{Al}_{3} \mathrm{Sc}_{1-\mathrm{x}} \mathrm{Zr}_{\mathrm{x}}$ particles, although their further growth and coarsening is evident (Figure 7d). 


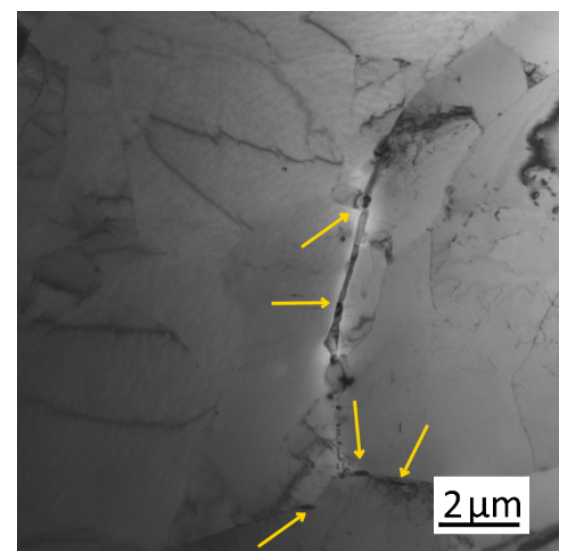

(a)

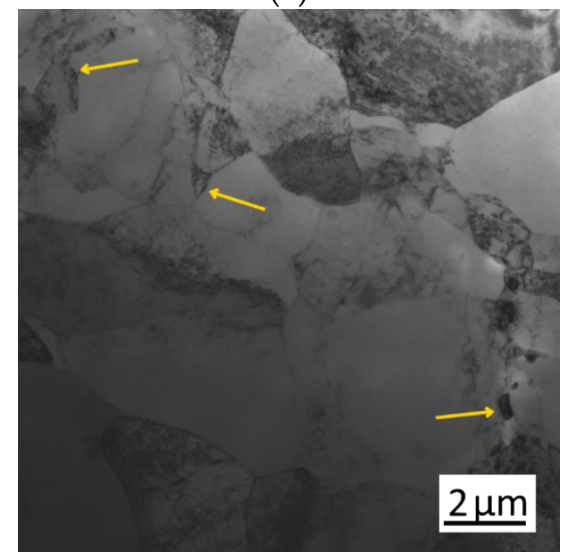

(c)

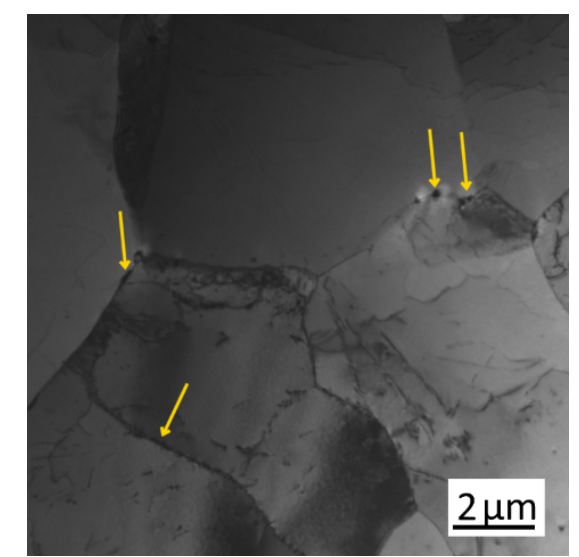

(b)

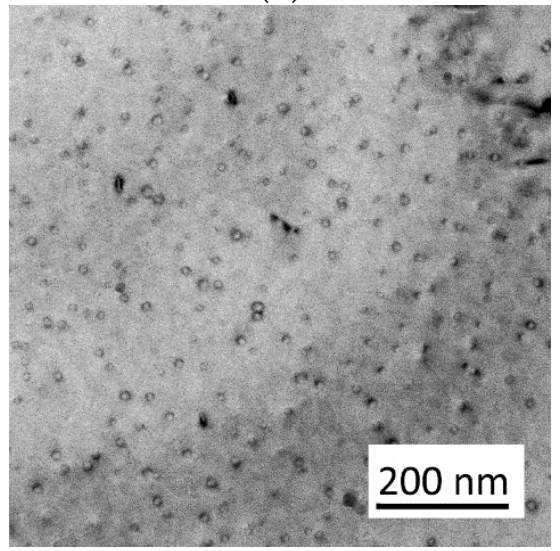

(d)

Figure 7. TEM bright field images of grain boundary particles after linear heating up to $500{ }^{\circ} \mathrm{C}$ and further artificial aging $500^{\circ} \mathrm{C} / 80 \mathrm{~min}$ in Al-Li-Cu-Mg-Zr alloy (a,b) and Al-Li-Cu-Mg-Zr-Sc alloy (c). Particles of $\mathrm{Al}_{3} \mathrm{Sc}_{1-\mathrm{x}} \mathrm{Zr}_{\mathrm{x}}$ phase in Al-Li-Cu-Mg-Zr-Sc alloy (d).

The positive impact of $\mathrm{Al}_{3} \mathrm{Sc}_{1-\mathrm{x}} \mathrm{Zr}_{\mathrm{x}}$ particles on the stability of grains is illustrated in Figure 8. While only negligible changes in grain size distribution due to TRC could be observed in the Al-Li-Cu-Mg-Zr-Sc alloy (Figure 8a), significant recrystallization and grain growth occur in the Sc-free alloy (Figure $8 b$ ). However, even exposing both materials to $500{ }^{\circ} \mathrm{C}$ for $80 \mathrm{~min}$ did not result in a full dissolution of the particles that cover new or initial grain boundaries (Figure $8 \mathrm{c}, \mathrm{d}$, and details in Figure 9a,b). This indicates possible limitations of the alloys, since non-equilibrium phases with a low melting point could melt at temperatures close to $500{ }^{\circ} \mathrm{C}$, which in turn could lead to a deterioration of the strip properties during homogenization [52], necessitating the development of a multi-stage homogenization treatment. 


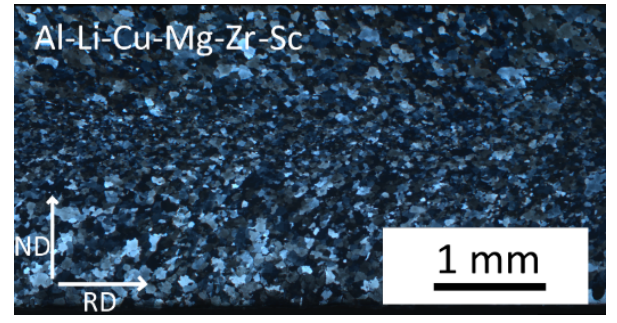

(a)

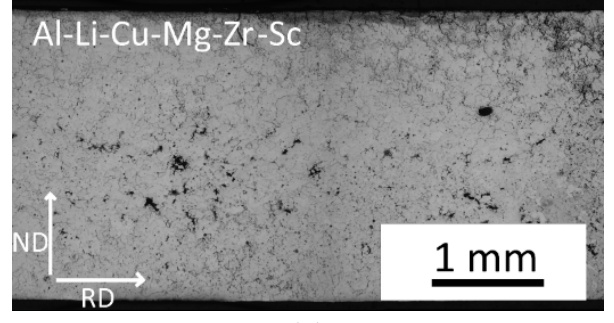

(c)

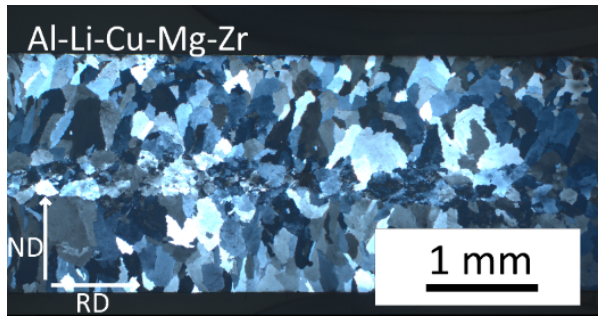

(b)

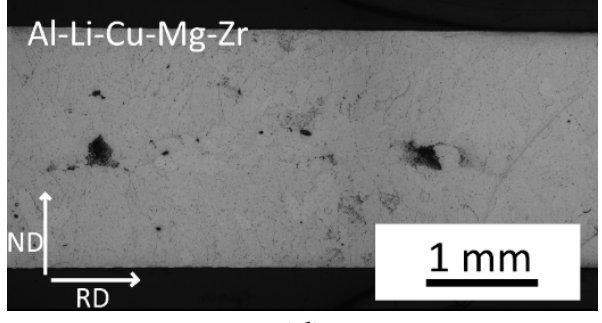

(d)

Figure 8. Grain structure $(\mathbf{a}, \mathbf{b})$ and distribution of eutectic phases $(\mathbf{c}, \mathbf{d})$ in both alloys after linear heating up to $500^{\circ} \mathrm{C}$ and further artificial aging $500{ }^{\circ} \mathrm{C} / 80 \mathrm{~min}$.

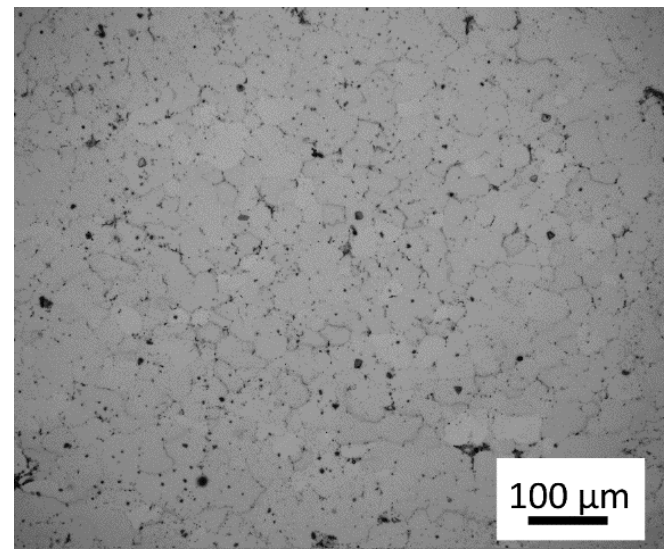

(a)

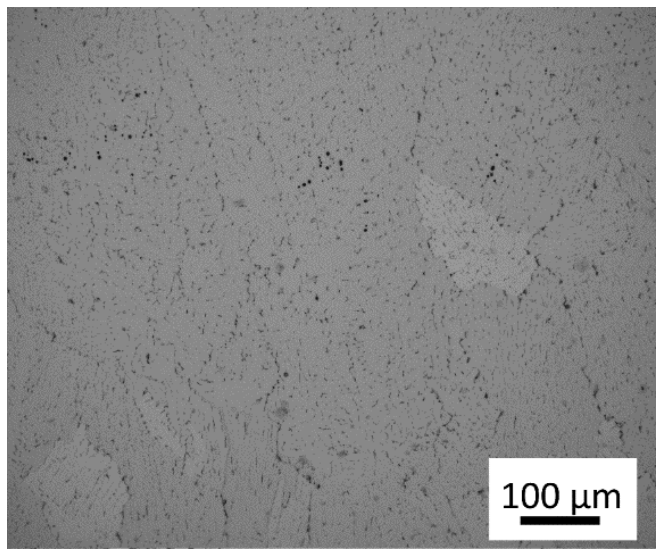

(b)

Figure 9. Details of particles distribution in Al-Li-Cu-Mg-Zr-Sc (a) and Al-Li-Cu-Mg-Zr (b) alloys after linear heating up to $500{ }^{\circ} \mathrm{C}$ and further artificial aging $500{ }^{\circ} \mathrm{C} / 80 \mathrm{~min}$.

\section{Conclusions}

- Strips of two Al-Li based alloys with and without the addition of Sc were produced by twin-roll casting.

- A fine dendritic structure forms during the processing by twin-roll casting.

- Sc alloying results in the formation of finer grains already during casting.

- $\mathrm{Al}_{3} \mathrm{Sc}_{1-\mathrm{x}} \mathrm{Zr}_{\mathrm{x}}$ particles precipitate in the Sc-containing alloy at temperatures near $400{ }^{\circ} \mathrm{C}$.

- The as-cast grain structure is replaced by a recrystallized and coarsened structure in the Sc-free alloy at temperatures close to $500^{\circ} \mathrm{C}$.

- The presence of $\mathrm{Al}_{3} \mathrm{Sc}_{1-\mathrm{x}} \mathrm{Zr}_{\mathrm{x}}$ particles effectively inhibits recrystallization, and even at the highest annealing temperatures no grain growth occurs in the Al-Li-Cu-Mg-Zr-Sc alloy.

- Primary phases formed during casting could not dissolve below $500{ }^{\circ} \mathrm{C}$, which could limit the properties of new twin-roll cast alloys. 
Author Contributions: O.G. designed the twin-roll casting process, contributed to interpretation of process-microstructure relationships and participated in the writing of the manuscript, M.S. (Mykhailo Stolbchenko) conducted the twin-roll casting trials and M.S. (Mirko Schaper). supervised the research activities. S.B. and R.K. performed the annealing of the specimens and LOM observations, M.H. was responsible for resistivity measurements, L.B. and B.K. performed TEM analyses and M.C. was responsible for compiling the results and contributed to the writing of the manuscript. All authors have read and agreed to the published version of the manuscript.

Funding: This research was partially funded by CZECH SCIENCE FOUNDATION, grant number 20-19170S.

Conflicts of Interest: The authors declare no conflict of interest.

\section{References}

1. Abd El-Aty, A.; Xu, Y.; Zhang, S.H.; Ma, Y.; Chen, D.Y. Experimental investigation of tensile properties and anisotropy of 1420, 8090 and 2060 Al-Li alloys sheet undergoing different strain rates and fibre orientation: A comparative study. Procedia Eng. 2017, 207, 13-18. [CrossRef]

2. Barekar, N.S.; Das, S.; Yang, X.; Huang, Y.; El Fakir, O.; Bhagurkar, A.G.; Zhou, L.; Fan, Z. The impact of melt conditioning on microstructure, texture and ductility of twin roll cast aluminium alloy strips. Mater. Sci. Eng. A 2016, 650, 365-373. [CrossRef]

3. Rioja, R.; Liu, J. The evolution of Al-Li base products for aerospace and space applications. Metall. Mater. Trans. A 2012, 43, 3325-3337. [CrossRef]

4. Lavernia, E.J.; Srivatsan, T.S.; Mohamed, F.A. Strength, deformation, fracture behaviour and ductility of aluminium-lithium alloys. J. Mater. Sci. 1990, 25, 1137-1158. [CrossRef]

5. Prasad, N.E.; Gokhale, A.A.; Rao, P.R. Mechanical behaviour of aluminium-lithium alloys. Sadhana 2003, 28, 209-246. [CrossRef]

6. Alexopoulos, N.; Migklis, E.; Stylianos, A.; Myriounis, D.P. Fatigue behavior of the aeronautical Al-Li (2198) aluminum alloy under constant amplitude loading. Int. J. Fatigue 2013, 56, 95-105. [CrossRef]

7. Kashyap, B.; Chaturvedi, M. Stain anisotropy in AA8090 Al-Li alloy during high temperature deformation. Mater. Sci. Eng. A 2020, 281, 88-95. [CrossRef]

8. Qin, H.; Zhang, H.; Wu, H. The evolution of precipitation and microstructure in friction stir welded 2195-T8 Al-Li alloy. Mater. Sci. Eng. A 2015, 625, 322-329. [CrossRef]

9. Lavernia, E.J.; Grant, N.J. Aluminium-lithium alloys. J. Mater. Sci. 1987, 22, 1521-1529. [CrossRef]

10. Dursun, T.; Soutis, C. Recent developments in advanced aircraft aluminium alloys. Mater. Des. 2014, 56, 862-871. [CrossRef]

11. Prasad, K.; Prasad, N.; Gokhale, A. Microstructure and precipitate characteristics of aluminum-lithium alloys. In Aluminum-Lithium Alloys: Processing, Properties, and Applications; Prasad, N.E., Gokhale, A., Wanhill, H., Eds.; Elsevier Inc.: Oxford, UK, 2014; pp. 99-137.

12. Srivatsan, T.; Lavernia, E.; Eswara Prasad, N.; Kutumbarao, V. Quasi-static strength, deformation, and fracture behavior of aluminum-lithium alloys. In Aluminum-Lithium Alloys: Processing, Properties, and Applications; Prasad, N.E., Gokhale, A., Wanhill, H., Eds.; Elsevier Inc.: Oxford, UK, 2014; pp. 305-339.

13. Ashton, R.F.; Thompson, D.S.; Gayle, F.W. The effect of processing on the properties of Al-Li alloys. In Aluminum Alloys-Their Physical and Mechanical, Properties; Starke, J., Sanders, J., Eds.; EMAS: Warley, UK, 1986; pp. 403-417.

14. Noble, B.; Harris, S.J.; Dinsdale, K. Yield characteristics of aluminium-lithium alloys. Met. Sci. 1982, 16, 425-430. [CrossRef]

15. Lin, F.; Chakraborty, S.; Starke, E. Microstructure-property relationships of two Al-3Li-2Cu-0.2Zr-X Cd alloys. Metall. Trans. A 1982, 13, 401-410. [CrossRef]

16. Suresh, S.; Vasudevan, A.; Tosten, M.; Howell, P. Microscopic and macroscopic aspects of fracture in lithium containing aluminium alloys. Acta Metall. 1987, 35, 25-46. [CrossRef]

17. Srivatsan, T.S.; Place, T.A. Microstructure, tensile properties and fracture behaviour of an Al-Cu- $\mathrm{Li}-\mathrm{Mg}-\mathrm{Zr}$ alloy 8090. J. Mater. Sci. 1989, 24, 1543-1551. [CrossRef]

18. Jata, K.V.; Starke, E.A. Fatigue crack growth and fracture toughness behavior of an Al-Li-Cu alloy. Metall. Trans. A 1986, 17, 1011-1026. [CrossRef] 
19. Peel, C.; McDarmaid, D.; Evans, B. Considerations of critical factors for the design of aerospace structures using current and future Al-Li alloys. In Aluminium_Lithium Alloys: Design, Development and Applications Update; Kar, S.J., Agarwal, R., Quist, S., Eds.; ASM: International Park, OH, USA, 1988; pp. 315-337.

20. Marquis, E.A.; Seidman, D.N. Nanoscale structural evolution of Al3Sc precipitates in $\mathrm{Al}(\mathrm{Sc})$ alloys. Acta Mater. 2001, 49, 1909-1919. [CrossRef]

21. Ferry, M. Direct Strip Casting of Metals and Alloys, 1st ed.; Woodhead Publishing Limited: Cambridge, UK, 2006.

22. Zhu, Y.T.; Jiang, H.; Huang, J.; Lowe, T.C. A new route to bulk nanostructured metals. Metall. Mater. Trans. A 2001, 32, 1559-1562. [CrossRef]

23. Shin, D.H.; Park, J.J.; Kim, Y.S.; Park, K.T. Constrained groove pressing and its application to grain refinement of aluminum. Mater. Sci. Eng. A 2002, 328, 98-103. [CrossRef]

24. Valiev, R.Z.; Estrin, Y.; Horita, Z.; Langdon, T.G.; Zehetbauer, M.J.; Zhu, Y.T. Producing bulk ultrafine-grained materials by severe plastic deformation. JOM 2006, 58, 33-39. [CrossRef]

25. Barekar, N.S.; Dhindaw, B.K. Twin-roll casting of aluminum alloys-An overview. Mater. Manuf. Process. 2014, 29, 651-661. [CrossRef]

26. Wang, L.; Yu, H.; Lee, Y.S.; Kim, M.S.; Kim, H.W. Effect of microstructure on hot tensile deformation behavior of 7075 alloy sheet fabricated by twin roll casting. Mater. Sci. Eng. A 2016, 652, 221-230. [CrossRef]

27. Park, Y.S.; Lee, S.B.; Kim, N.J. Microstructure and mechanical properties of strip cast Al-Mg-Si-X alloys. Mater. Trans. 2003, 44, 2617-2624. [CrossRef]

28. Birol, Y. Analysis of macro segregation in twin-roll cast aluminium strips via solidification curves. J. Alloys Compd. 2009, 486, 168-172. [CrossRef]

29. Birol, Y. Homogenization of a twin-roll cast thin Al-Mn strip. J. Alloys Compd. 2009, 471, 122-127. [CrossRef]

30. Altuner, H.M.; Işıksaçan, C.; Birbaşar, O.; Günyüz, M.; Meydanoğlu, O. Crystallographic texture development of As-Cast 3105 alloy produced by St/Cu shell pair. In Light Metals; Williams, E., Ed.; Springer: Cham, Switzerland, 2016; pp. 1025-1030. [CrossRef]

31. Schmidt, C.W.; Mortensen, D.; Karhausen, K.F. Influence of Process Conditions on Segregation Behavior in Twin-Roll Casting of an AlFeSi-Alloy. In Light Metals; Springer: Cham, Switzerland, 2017; pp. 811-819. [CrossRef]

32. Hoseinifar, A.; Salari, S.; Nezhad, M. Effect of twin-roll casting parameters on microstructure and mechanical properties of AA5083-H321 sheet. Trans. Nonferrous Met. Soc. China 2016, 26, 2552-2560. [CrossRef]

33. Haga, T.; Tkahashi, K.; Ikawaand, M.; Watari., H. Twin roll casting of aluminum alloy strips. J. Mater. Process. Technol. 2004, 153-154, 42-47. [CrossRef]

34. Birol, Y. Pre-aging to improve bake hardening in a twin-roll cast Al-Mg-Si alloy. Mater. Sci. Eng. A 2005, 391, 175-180. [CrossRef]

35. Chen, H.; Li, Y.; Li, J.D.; Gao, G.J.; Wang, Z.D. 6000 series aluminium alloy strip casting using a vertical type twin roll caster. Mater. Sci. Forum 2016, 877, 45-50. [CrossRef]

36. Grydin, O.; Schaper, M.; Danchenko, V. Twin-roll casting of high-strength age-hardened aluminium alloys. Metall. Min. Ind. 2011, 3, 7-16.

37. Cieslar, M.; Bajer, J.; Zimina, M.; Šlapáková, M.; Grydin, O. Properties and microstructure of twin-roll cast Al-Mg alloy containing Sc and Zr. In Proceedings of the 4th International Conference Recent Trends in Structural Materials, Pilsen, Czech Republic, 9-11 November 2016; IOP Publishing Ltd.: Bristol, UK, 2017.

38. Li, S.; He, C.; Fu, J.; Xu, J.; Xu, G.; Wang, Z. Evolution of microstructure and properties of novel aluminumlithium alloy with different roll casting process parameters during twin-roll casting. Mater. Charact. 2020, 161, 110145. [CrossRef]

39. Grydin, O.; Ogins'kyy, Y.K.; Danchenko, V.M.; Bach, F.W. Experimental twin-roll casting equipment for production of thin strips. Metall. Min. Ind. 2010, 2, 348-354.

40. Grydin, O.; Stolbchenko, M.; Nürnberger, F.; Schaper, M. Influence of the twin-roll casting parameters on the microsegregation in thin strips of the aluminium alloy EN AW-6082. In Light Metals 2014; Springer: Cham, Switzerland, 2014; pp. 411-414.

41. Grydin, O.; Stolbchenko, M.; Schaper, M. Influence of nozzle shape on near-surface segregation formation during twin-roll casting of aluminum strips. In Light Metals 2020; Springer: Cham, Switzerland, 2020; pp. 1039-1044. 
42. Yun, M.; Lokyer, S.; Hunt, J.D. Twin roll casting of aluminium alloys. Mater. Sci. Eng. A 2000, 280, $116-123$. [CrossRef]

43. Song, R.; Harada, Y.; Murashi, S.; Kumai, S. Microstructural evolution of Al-Mn based alloy fabricated by vertical-type high-speed twin-roll casting. Mater. Sci. Forum 2016, 877, 51-55. [CrossRef]

44. Lockyer, S.A.; Yun, M.; Hunt, J.D.; Edmonds, D.V. Micro- and macrodefects in thin sheet twin-roll cast aluminum alloys. Mater. Charact. 1996, 37, 301-310. [CrossRef]

45. Monaghan, D.J.; Henderson, M.B.; Hunt, J.D.; Edmonds, D.V. Microstructural defects in high productivity twin-roll casting of aluminium. Mater. Sci. Eng. A 1993, 173, 251-254. [CrossRef]

46. Rioja, R.J. Fabrication methods to manufacture isotropic Al-Li alloys and products for space and aerospace applications. Mater. Sci. Eng. A 1998, 257, 100-107. [CrossRef]

47. Araullo-Peters, V.; Gault, B.; de Gauser, F.; Dechamps, A.; Cairney, J.M. Microstructural evolution during ageing of Al-Cu-Li-x alloys. Acta Mater. 2014, 66, 199-208. [CrossRef]

48. Huang, B.P.; Zheng, Z.Q. Independent and combined roles of trace $\mathrm{Mg}$ and $\mathrm{Ag}$ additions in properties precipitation process and precipitation kinetics of $\mathrm{Al}-\mathrm{Cu}-\mathrm{Li}-(\mathrm{Mg})-(\mathrm{Ag})-\mathrm{Zr}-\mathrm{Ti}$ alloys. Acta Mater. 1998, 46, 4381-4393. [CrossRef]

49. Hájek, M.; Veselý, J.; Cieslar, M. Precision of electrical resistivty measurements. Mater. Scie. Eng. A 2007, 462, 339-342. [CrossRef]

50. Decreaux, B.; Deschamps, A.; de Geuser, F.; Donnadieu, P.; Sigli, C.; Weyland, M. The influence of Cu/Li ratio on precipitation in Al-Cu-Li-x alloys. Acta Mater. 2013, 61, 2207-2218. [CrossRef]

51. Nes, E.; Ryum, N.; Hunderi, O. On the Zener drag. Acta Metall. 1985, 33, 11-22. [CrossRef]

52. Romios, M.; Tiraschi, R.; Parrish, C.; Babel, H.W.; Ogren, J.R.; Es-Said, O.S. Design of multistep aging treatments of 2099(C458) Al-Li alloy. J. Mater. Eng. Perform 2005, 14, 641-646. [CrossRef]

(C) 2020 by the authors. Licensee MDPI, Basel, Switzerland. This article is an open access article distributed under the terms and conditions of the Creative Commons Attribution (CC BY) license (http://creativecommons.org/licenses/by/4.0/). 